\title{
COMPARISON OF SUPPORT VECTOR MACHINE AND OBJECT BASED CLASSIFICATION METHODS FOR COASTLINE DETECTION
}

\author{
K. Kalkan ${ }^{\mathrm{a}}$, B. Bayram ${ }^{\mathrm{b}}$, D. Maktav ${ }^{\mathrm{a}}$, F. Sunar ${ }^{\mathrm{a}}$ \\ ${ }^{a}$ ITU, Civil Engineering Faculty, Department of Geomatics Engineering, 34469, Maslak Istanbul, Turkey - \\ (kalkank, maktavd, sunarf)@itu.edu.tr \\ ${ }^{\mathrm{b}}$ YTU, Civil Engineering Faculty, Department of Geomatics Engineering, 34330, Davutpaşa, Istanbul, Turkey - \\ bayram@ytu.edu.tr
}

KEY WORDS: Coastline detection, object-based classification (OBC), support vector machine (SVM)

\begin{abstract}
:
Detection of coastline is an important procedure for management of coastal zones. According to the International Geographic Data Committee (IGDC), coastlines are one of the most important environmental heritages on the earth's surface. In the coastal areas, main challenge is to understand the present coastline dynamics and to predict its future developments. Therefore the coastal zone monitoring is an essential process for sustainable coastal management and environmental protection. Shoreline extraction is an important issue for coastal zone monitoring.
\end{abstract}

In this study, efficiency of two different methods for detection of coastline features from satellite images, which cover Lakeland region of Turkey, has been tested. Firstly, object based classification method (OBC) has been used to extract shoreline automatically. Developed process based rule set extracts coastline as a vector file from satellite imagery. As a second method, support vector machine (SVM) algorithm has been used to extract coastline. For the application of these two different methods, Landsat 8 data have been used. The results of these two automatic coastline extraction methods were compared with the results derived from manual digitization process. Random control points over the coastline were used in the evaluation. Results showed that both methods have a sub-pixel accuracy to detect coastline features from Landsat 8 imagery.

\section{INTRODUCTION}

Comprehensive coastal zone management and erosion/flood control require a reliable and practical tool for predicting shoreline evolution in order to optimize shore protection measures. One way of supplying reliable information for coastal zone management is remote sensing. It provides the opportunity for precise and accurate monitoring of changes in coastal morphology for areas of concern (Bayram, et. al, 2008). As International Geographic Data Committee (IGDC) has mentioned, coastlines are one of the most important environmental heritages on the earth's surface (Kurt, et al., 2010).

Remote sensing techniques are important and useful tools for extracting coastal features (Kennedy et al.; 2009; Maiti and Bhattacharya, 2009; Bhaskaran et al., 2010). In this study, two coastline features detected from Landsat 8 imagery (acquisition date: 27.04.2013) by using object based classification and SVM approach have been compare. Study area covers Eğirdir lake which is in the lakeland region of Turkey (Figure 1.).

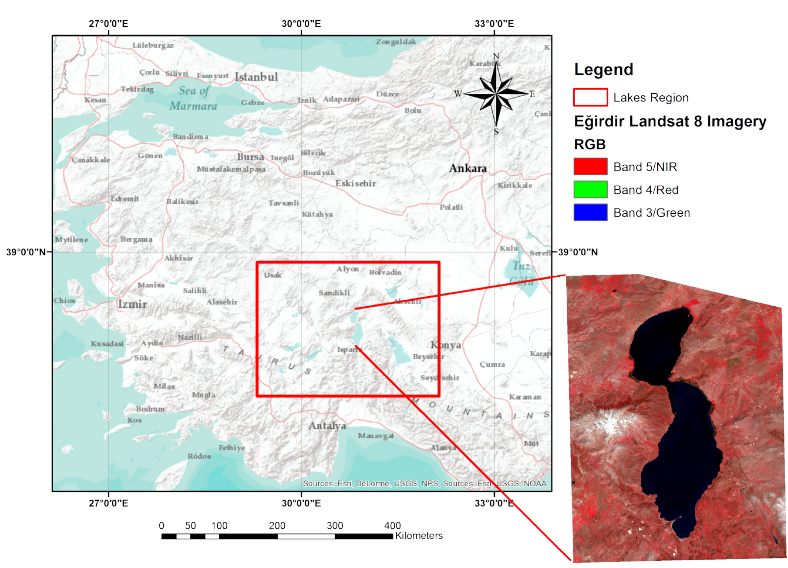

Figure 1. Study area, Eğirdir Lake, Turkey

\section{METHODOLOGY}

a) Object based image analysis is a useful technique to classify remote sensing imagery especially with very high resolution (VHR). The basic processing units of object-oriented image analysis are segments, so-called image objects, and no single pixels. Advantages of object-oriented analysis are meaningful statistic and texture calculation, an increased uncorrelated feature space using shape (e.g. length, number of edges, etc.) and topological features (neighbor, super-object, etc.), and the close relation between real-world objects and image objects. This relation improves the value of the final classification and cannot be fulfilled by common, pixel-based approaches. Segmentation in eCognition software (Baatz and Schape,2000; Baatz and Mimler, 2002) allows both segmentation based on primary features (gray tone and shape) and-after an initial classification - the more advanced classification-based segmentation. The method is applicable for many data types with different dynamic and distribution. Constraints can be used 
to ensure exact reproducibility of segmentation. (Benz et al, 2003) Object-based remote sensing image information extraction technology is useful and efficient in the application to the research of land use change. Object based image analysis (OBIA) uses not only spectral information but also image geometry and morphologic information of the image for object extraction which is the main difference of OBIA from other pixel based approaches. (Zhao, et al., 2010).

In this study, OBC method has been used with eCognition Developer software to classify water bodies from Landsat 8 imagery. Process-based rule set has been created by applying rules to create water surfaces. NDWI (Normalized Difference Water Index) (Gao, 1996) layer has been calculated by band ratio algorithm (near infrared - green / near infrared + green) to use within class feature description of water class (Figure 2a). Segmentation of Landsat 8 imagery has been calculated by using scale factor of " 50 " to detect homogenous surfaces which represent water bodies. Shape and Compactness values for homogeneity criterion have been applied as 0.5 . Seven layers of Landsat 8 imagery has been used for segmentation procedure (Coastal, Blue, Green, Red, NIR, SWIR1, and SWIR2). NDWI values which is smaller than 0 is classified as water surfaces and then merged. Water bodies have been extracted as a shape vector file to use in Geographic Information System (GIS) and comparison.

b) According to Keuchela, image classification can be performed in different ways e.g. supervised or unsupervised, contextual or non-contextual, parametric or nonparametric (2003). SVMs are nonparametric in the sense that they do not attempt to model the distribution of the training data, but try to separate the different classes by directly searching for adequate boundaries between them (Keuchela, 2003). Classical classifiers like maximum likelihood and minimum distance to means are different from SVMs as parametric classifiers. SVMs, like other nonparametric classifiers such as artificial neural networks, boast a robustness that has spearheaded its application into many areas. Having started off as a statistical learning theory (Vapnik, 1995), SVMs have continued to be used in machine vision fields such as character, handwriting digit and text recognition (Vapnik, 1995; Joachims, 1998). Recently, SVMs have a wide application range for land cover mapping (Kavzoglu et al, 2009, Anthony et al 2008, Song et al, 2011). Like other supervised classifiers, training data is a prerequisite to define the decision boundaries within the feature space, based upon which classification decision rules are made.

In this study, SVM classification of Landsat 8 imagery has been applied by using Radial Basis Function kernel type in ENVI software (gamma parameter $=0.143$ ). Training areas for water bodies have been selected homogeneously from satellite imagery to distinguish water bodies from other land cover types (Figure 2.b.). Classification result has been finalized by using rule classifier to produce thematic map of water bodies. Also, raster classification result has been vectorized also to compare with $\mathrm{OBC}$ results in GIS (Figure 3).

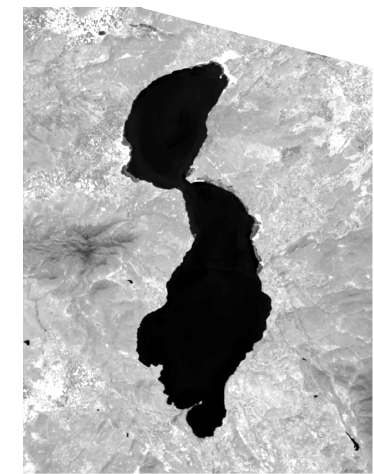

(a)

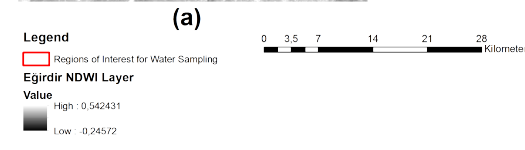

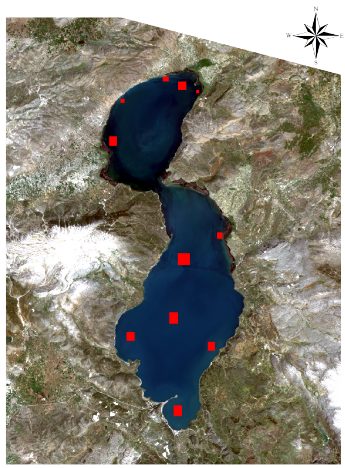

(b)
Figure 2. a) NDWI layer calculated with band arithmetic b) Training areas for SVM classification

\section{RESULTS}

In this study coastline detection efficiency of both $\mathrm{OBC}$ and SVM classifier tested. Both classification methods results' have different vector files from each other. Reference vector which is vectorized manually by using on-screen digitizing from satellite imagery is different from object based classification result. $\mathrm{OBC}$ result has pixel border effect which is more precise according to SVM classification result. Whereas OBC result is not smoothed, but manual digitizing has smoothing effect because of hand drawing (drawing from hypotenuse). So both classification results have different coastline length for Eğirdir Lake. OBC result $(160 \mathrm{~km})$ have larger coastline length according to manual digitizing $(149 \mathrm{~km})$, SVM result $(144 \mathrm{~km})$ is similar to manual digitizing. Comparison results of total lakes areas have also similar results. Area of Eğirdir Lake is $456 \mathrm{~km}^{2}$ according to manual digitizing result. Total lake surface area obtained using $\mathrm{OBC}$ is 0.5 percent larger than manual digitizing results. SVM classification gives 1 percent larger surface area than manual digitizing.

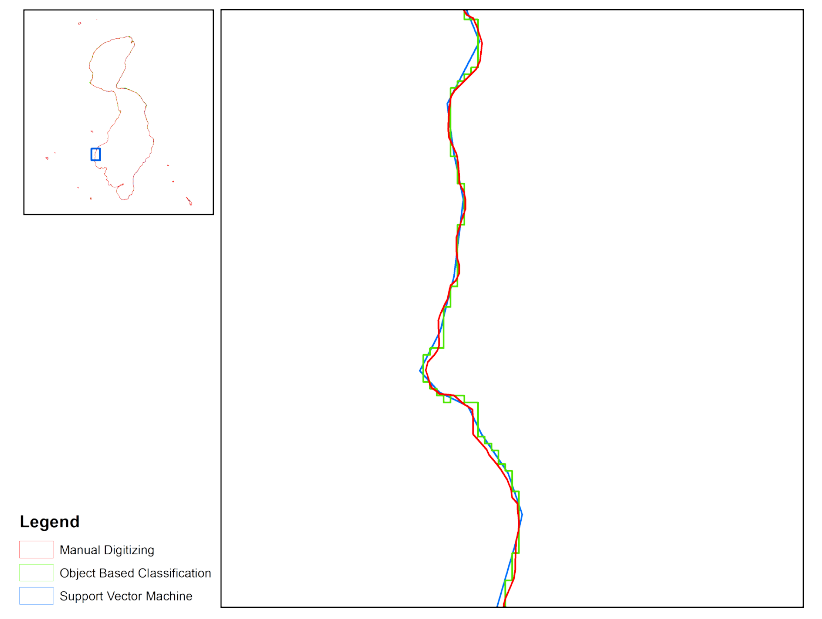

Figure 3. Comparison of coastline detection results in GIS

10 random points have been created on vector file of manual digitizing result to measure Euclidean distances of these points to OBC and SVM classification results. Results shown that both 
classifiers are capable to detect coastline features in sub-pixel accuracy (Table 1).

\begin{tabular}{|c|c|c|}
\cline { 2 - 3 } \multicolumn{1}{c|}{} & \multicolumn{2}{c|}{$\begin{array}{c}\text { Euclidean Distance to } \\
\text { Manual Classification }(\mathrm{m})\end{array}$} \\
\hline Point & OBC & SVM \\
\hline 1 & 15 & 23 \\
\hline 2 & 24 & 3 \\
\hline 3 & 27 & 28 \\
\hline 4 & 0 & 0 \\
\hline 5 & 3 & 2 \\
\hline 6 & 5 & 28 \\
\hline 7 & 10 & 11 \\
\hline 8 & 5 & 13 \\
\hline 9 & 16 & 0 \\
\hline 10 & 0 & 15 \\
\hline
\end{tabular}

Table 1. Euclidean distances of random points on manual digitizing result to $\mathrm{OBC}$ and $\mathrm{SVM}$ classification results

Vectorization problem of SVM classification is also important in evaluating of the results. SVM results image is vectorized to compare with other classifiers, this vectorization process cause missing information by smoothing which is similar to manual digitizing.

\section{CONCLUSION}

Although the main advantage of object based classification gives us an opportunity for setting specific customized features or calculation specific indices, accuracy of segmentation affects directly classification accuracy. In this study, it has been observed that, the mixed-pixel problem, which is the main problem of classification using pixel-based approach, is very much related to the quality of segmentation. Therefore the practical results of this study show that the setting of segmentation parameters has to be examined very carefully. Generally both classification methods have sub-pixel $(<30 \mathrm{~m})$ accuracy in detecting coastline features. As an advantage of OBC method, using additional layers like NDWI indices, increase the accuracy of classification. Both of these methods can be used to detect coastline features from Landsat 8 imagery. In addition to this, OBC methods can yield more precise coastline feature with high resolution satellite imagery. As and outcome of this study, usage of NIR layers to classify water bodies is an important procedure.

\section{REFERENCES}

Anthony, G., Gregg, H., Tshilidzi, M., 2008. An svm multiclassifier approach to land cover mapping. In ASPRS 2008 Annual Conference.

Baatz, M., Mimler, M., 2002. Bildobjekt-Primitive als Bausteine Extraktion von Objekten of interest bzw. anthropogenen Objekten basierend auf der expliziten Kanteninformation von Bildobjekt-Primitiven. In: Blaschke, T. (Ed.), GIS und Fernerkundung: Neue Sensoren - Innovative Methoden. Wichmann Verlag, Heidelberg, pp. 179 - 188.

Baatz, M., Schape, A., 2000. Multiresolution segmentation-an optimization approach for high quality multi-scale image segmentation. In: Strobl, J., Blaschke, T., Griesebner, G. (Eds.), Angewandte Geographische Informations-Verarbeitung XII. Wichmann Verlag, Karlsruhe, pp. $12-23$.
Bayram B., Acar U., Seker D., Ari A., 2008. "A Novel Algorithm for Coast Line Fitting Through A Case Study Over Bosporus", Journal of Coastal Research, 24(4), 983-991.

Benz, U.C., Hofmann, P., Willhauck, G., Lingenfelder, I., Heynen, M., 2004. Multi-resolution, object-oriented fuzzy analysis of remote sensing data for GIS-ready information. ISPRS Journal of Photogrammetry and Remote Sensing 58.

Bhaskaran, S., Paramananda, S., Ramnarayan, M., 2010. Perpixel and object-oriented classification methods for mapping urban features using Ikonos satellite data, Applied Geography. $30,650-665$.

Gao, B., 1996. NDWI-A normalized difference water index for remote sensing of vegetation liquid water from space, Remote Sensing of Environment, Volume 58, Issue 3, Pages 257-266.

Joachims, T., 1998. Text categorization with support vector machines-learning with many relevant features, In Proceedings of the 10th European Conference on Machine Learning, Chemnitz, Germany, Berlin: Springer, pp. 137-142.

Kavzoglu, T., Colkesen, I., 2009. A kernel functions analysis for support vector machines for land cover classification. International Journal of Applied Earth Observation and Geoinformation.

Kennedy, R.E., Townsend, P.A., Gross, J.E., Cohen, W.B., Bolstad, P., Wang, Y.Q., Adams, P., 2009. Remote sensing change detection tools for natural resource managers: Understanding concepts and trade-offs in the design of landscape monitoring projects, Remote Sensing of Environment. 113, 1382-1396.

Keuchela, J., Nauman, S., Heilera, M., and Siegmund, A., 2003. Automatic land cover analysis for Tenerife by supervised classification using remotely sensed data,. Remote Sensing of Environment, 86, 530-541.

Kurt, S., Karaburun, A., Demirci, A., 2010. Coastline changes in Istanbul between 1987 and 2007, Scientific Research and Essays, 5 (19), 3009-3017.

Maiti, S. and Bhattacharya, A.K., 2009. Shoreline change analysis and its application to prediction: A remote sensing and statistics based approach, Marine Geology, 257, 11-23.

Song, X., Duan, Z., Jiang, X., 2012. Comparison of artificial neural networks and support vector machine classifiers for land cover classification in Northern China using a SPOT-5 HRG image. International Journal of Remote Sensing, 33(10)

Vapnik, V. N., 1995. The Nature of Statistical Learning Theory, New York: Springer-Verlag.

Zhao, C.. Li, P., Li, X., 2010. Study on object-oriented information extraction technology and its application to LUCC in the northern coast of Hainan Island Remote Sensing of the Coastal Ocean, Land, and Atmosphere Environment. Edited by Frouin, Robert J.; Rhyong Yoo, Hong; Won, Joong-Sun; Feng, Aiping. Proceedings of the SPIE, Volume 7858, article id. 785814, $10 \mathrm{pp}$. 